\title{
GENDER AS A MODERATOR OF THE RELATIONSHIP BETWEEN POSITIVE AFFECT AND LIFE SATISFACTION
}

\author{
Malathie Dissanayake ${ }^{1}$, Shanmukh Kamble $^{2}$, Appasaheb Patil ${ }^{2}$ \\ ${ }^{1}$ South Asian Institute of Technology and Medicine \\ ${ }^{2}$ Karnatak University
}

\begin{abstract}
Experience of positive affect may help individuals to enhance psychological growth and well-being. This study examined the effect of positive affect on purpose in life and life satisfaction. Also, we intended to examine the moderating effect of gender on the link between positive affect and purpose in life and the link between positive affect and life satisfaction. The sample consisted of 200 participants (76 females and 124 males) and they responded to a questionnaire assessing positive affect, purpose in life and life satisfaction. Positive affect significantly predicted purpose in life and life satisfaction. There was a significant gender difference in purpose in life, that is, women rated higher on purpose in life than men. Further, the interaction between positive affect and gender was significant, indicating that the effect of positive affect on life satisfaction was moderated by gender.
\end{abstract}

Keywords: positive affect, purpose in life, life satisfaction, gender

\section{Introduction}

Emotions play a vital role in one's life. They produce reaction tendencies including subjective experience, physiological changes, and expressions. Affect is a more consciously accessible emotional state that is present within emotions (Fredrickson, 2001). It is also considered as more long-lasting affective state which may be relevant only at the level of subjective experience (Ekman, 1994; Rosenberg, 1998; Russell \& Barrett, 1999). Affect may be present within various other affective experiences including moods, attitudes, and affective traits (Fredrickson, 2001). It varies along two extents: either pleasantness and activation (Russell \& Barrett, 1999) or positive and negative affective activation (Tellegen, Watson, \& Clark, 1999).

Affect plays an important role in maintaining one's health and well-being. Particularly, experience of positive affect has favorable influence on one's personal growth, social relationships, life satisfaction and overall wellbeing. Positive affect can be a result of a positive experience of an individual. Many researchers have stated the influence of positive affect on behaviors that are directed towards more desired outcomes (Cacioppo, Gardner, \& Berntson, 1999; Davidson, 1993; Watson, Wiese, Vaidya, \& Teilegen, 1999) or continued action (Carver \& Scheier, 1990; Clore, 1994). Experiences of positive affect may have greater benefits for individuals in their daily living. For example, positive affect may motivate individuals to connect with their environments and also to get involved in activities that increase happiness and life satisfaction (Fredrickson, 2001).

In addition, positive affect may promote one's well-being. Research has found evidence for the vital role of positive affect in maintaining and enhancing one's well-being. For example, positive affect seems to be associated with individuals' perceptions of general health (Trankle \& Haw, 2009). Accordingly, individuals who experience positive affect have a greater tendency to value their health. Positive feelings may encourage individuals to engage in desirable activities that enhance health and well-being. According to Broaden-andBuild theory, there are many benefits of positive affect. Positive feelings change individuals' state of mind. Positive affect expand one's attention (Fredrickson \& Branigan, 2005; Rowe, Hirsch, \& Anderson, 2007), 
widens behavioral repertoires (Fredrickson \& Branigan, 2005), and improve creativity (Isen, Daubman, \& Nowicki, 1987) as well as intuition (Bolte, Goschkey, \& Kuhl, 2003).

Positive feelings also have more desirable mental health outcomes such as improving psychological growth (Fredrickson, Tugade, Waugh, \& Larkin, 2003), and increasing happiness (Fredrickson \& Joiner, 2002) as well as resilience to adversity (Fredrickson, Tugade, Waugh, \& Larkin, 2003). With respect to physical health, a considerable body of research has underscored the importance of positive affect in improving physical wellbeing. For example, positive affect impact on physical health outcomes such as reduced inflammatory responses to stress (Steptoe et al., 2005), lower levels of cortisol (Steptoe, Wardle, \& Marmot, 2005) and reductions in stroke (Ostir, Markides, Peek, \& Goodwin, 2001). Research has also demonstrated a significant association between positive affect and longevity (Danner, Snowdon, \& Friesen, 2001; Levy, Slade, Kunkel, \& Kasl, 2002; Moskowitz, 2003; Ostir, Markides, Black, \& Goodwin, 2000) suggesting that frequent experience of positive affect helps individuals live a long and happy life.

\section{Positive affect and purpose in life}

Purpose in life is one of the key elements of Ryff's model of psychological well-being. It can be defined as one's belief that life is meaningful and having life goals (Ryff, 1995). According to Ryff, individuals with a strong feeling of purpose in life tend to have goals in their lives and have a sense of directedness towards these goals. Also, they believe that there is a meaning to present as well as past life and they hold beliefs that give them life purpose. On the other hand, individuals with a weak sense of purpose in life tend to have few goals in their lives and lack of sense of purpose. They seem to have a poor sense of direction and they do not see a meaning of their past life. Additionally, they do not have beliefs that give meaning to their lives. Research has found gender differences in purpose in life (Ryff, 1995). Accordingly, young men tend to score higher than women on purpose in life.

In more individualistic societies (e.g., United States), positive affect is valued as an optimistic social norm that promote desirable attributes associated with one's goal (Yoo, Miyamoto, \& Ryff, 2016). According to Broadenand-Build theory, daily experience of positive emotions helps individuals develop personal resources such as purpose in life, mindfulness, and social support (Fredrickson, 1998, 2001). Research has also demonstrated that positive affect significantly impact on individuals to feel that life is meaningful. Positive moods influence them to become more sensitive to the meaning-relevance of social events or situations (King, Hicks, Krull, \& Del Gaiso, 2006).

\section{Positive affect, purpose in life, and life satisfaction}

A considerable body of research has demonstrated intercorrelations among positive affect, purpose in life, and life satisfaction (Chamberlain \& Zika, 1988; King, Hicks, Krull, \& Del Gaiso, 2006; Ryff, 1989; Zika \& Chamberlain, 1992). One's subjective well-being consists of a cognitive as well as an affective element (Diener et al., 1999). The cognitive element includes overall appraisal or the satisfaction with various aspects of life whereas the affective component of subjective well-being assesses an individual's affective state (experience of both positive and negative feelings). Affect may influence individuals' perceptions of themselves as well as their lives. Experience of positive emotions in everyday life contributes to build personal resources including psychological, cognitive, and social resources and thereby increasing life satisfaction (Cohn, Fredrickson, Brown, Mikels, \& Conway, 2009).

In addition, a strong feeling of purpose in life seems to have various psychological outcomes. Several studies have suggested that purpose in life is associated with global happiness (Debats, van deLubbe, \& Wezeman, 1993; Park, Park, \& Peterson, 2010; Ryff \& Keyes, 1995) and life satisfaction (Chamberlain \& Zika, 1988; Steger, Kashdan, Sullivan, \& Lorentz, 2008; Steger, Oishi, \& Kashdan, 2009). Further, research findings have indicated that higher level of positive affect is related to higher self-rated health as well as better health-related 
behaviors (Yoo, Miyamoto, \& Ryff, 2016). Hence, positive affect and emotions help individuals maintain healthy life as well as achieve life satisfaction.

The major purpose of this study was to examine the relationships among positive affect, purpose in life and life satisfaction. We presumed that positive affect would be positively correlated with purpose in life as well as life satisfaction. Also, we hypothesized that men would rate higher on purpose in life than women. Finally, we assessed the role of gender in the association between positive affect and life satisfaction.

\section{Method}

\section{Participants}

The data were obtained from a convenience sample of 200 participants including 76 females and 124 males. The participants, whose ages vary from 18 and 28, were Indian adults in the Karnataka State. They were informed that their participations were completely voluntary. Demographic questions were used to obtain participants' information including age, gender, marital status, religion, ethnicity, area of living, level of education, and occupation.

\section{Materials}

Positive and negative affect scale. Positive Affect and Negative Affect Scale was used to examine individuals' affect (PANAS; Watson, Clark, \& Tellegen, 1988). The scale included 20 items: 10 positive (e.g., enthusiastic) and 10 negative (e.g., scared) adjectives rated on a 5-point scale $(1=$ very slightly or not at all and $5=$ extremely). The Cronbach alpha value for positive and negative affect was reported to be .85 and .90 respectively (Ostir, Smith, Smith, \& Ottenbacher, 2005). In this study, alpha value for positive affect was $\alpha=$ .71 and for negative affect was $\alpha=.86$.

Purpose in life. The 14-item Purpose in Life Scale of Ryff's psychological well-being inventory (1989) was used to measure purpose in life. Items such as "I have a sense of direction and purpose in life", "I am an active person in carrying out the plans I set for myself" were rated on a 6-point Likert scale ( $1=$ strongly disagree to 6 $=$ strongly agree). Reliability of this scale was $\alpha=.90$ (Ryff, 1989a). In this study, Cronbach's alpha value was $\alpha=.86$.

Life satisfaction. A 5-item self-report measure of satisfaction with life was used to assess Individuals' overall life satisfaction (SWLS; Diener, Emmons, Larsen, \& Griffin, 1985). Items were answered on a 7-point Likert scale $(1=$ strongly disagree and $7=$ strongly agree $)$. An example of items was: "So far I have gotten the important things I want in life." The Cronbach alpha value of this scale ranged from .85 to .92 (Kang et al. 2003). Reliability in the current study was determined to be $\alpha=.70$.

\section{Results}

Descriptive statistics of the main variables are presented in Table 1. There was a significant gender difference in relation to purpose in life. That is, women scored higher than men on purpose in life scale $(\mathrm{M}=4.74, \mathrm{SD}=.63$ for women, $\mathrm{M}=4.43, \mathrm{SD}=.83$ for men) (see Figure 1). This suggests that women have a stronger sense of meaning in life than men. 
Table 1 : Means and standard deviations for all measures

\begin{tabular}{lll}
\hline Measures & M & SD \\
\hline Positive affect & 3.98 & 0.51 \\
Negative affect & 2.40 & 0.78 \\
Purpose in life & 5.13 & 1.06 \\
Satisfaction with life & 4.55 & 0.77 \\
\hline
\end{tabular}

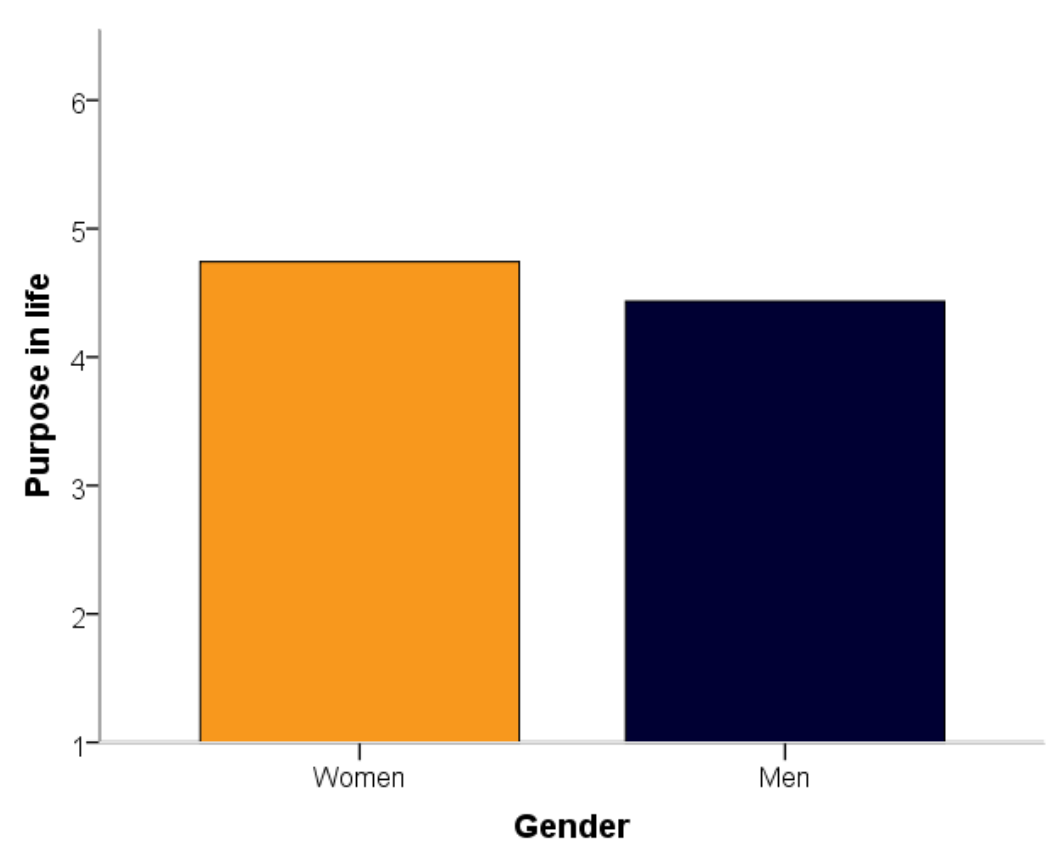

Figure 1. Gender difference in purpose in life

\section{Relationships among positive affect, purpose in life and life satisfaction}

The intercorrelations of the three main variables were significant for all variables: positive affect, purpose in life, and life satisfaction (see Table 2). Positive affect was significantly correlated with purpose in life suggesting that individuals who experience more positive affect tend to have stronger sense of purpose in life. Also, there was a significant correlation between positive affect and life satisfaction. It suggests that individuals who experience more positive affect are more satisfied with their lives. Further, the relationship between purpose in life and life satisfaction was also significant suggesting that those who have a stronger sense of purpose in life tend to experience greater feelings of satisfaction.

Table 2: Inter-correlations among positive affect, purpose in life and life satisfaction

\begin{tabular}{lll} 
Variables & Positive affect & Life satisfaction \\
\hline Life satisfaction & $.32^{* *}$ & \\
Purpose in life & $.31^{* *}$ & $.41^{* *}$ \\
\hline
\end{tabular}




\section{Moderating effect of gender on the link between positive affect and life satisfaction}

Hierarchical multiple regression analysis was conducted to test whether gender moderates the relationship between positive affect and life satisfaction. Tables 3 provides the results of the hierarchical multiple regression analysis predicting life satisfaction. Accordingly, positive affect significantly predicted life satisfaction. The regressions showed that gender did moderate the relationship between positive affect and life satisfaction $(\beta$ $=1.88, \mathrm{p}<.05)$.

Table 3: Hierarchical Regression Models with Positive Affect Predicting Life Satisfaction and the Moderating Effect of Gender ( $n=200)$

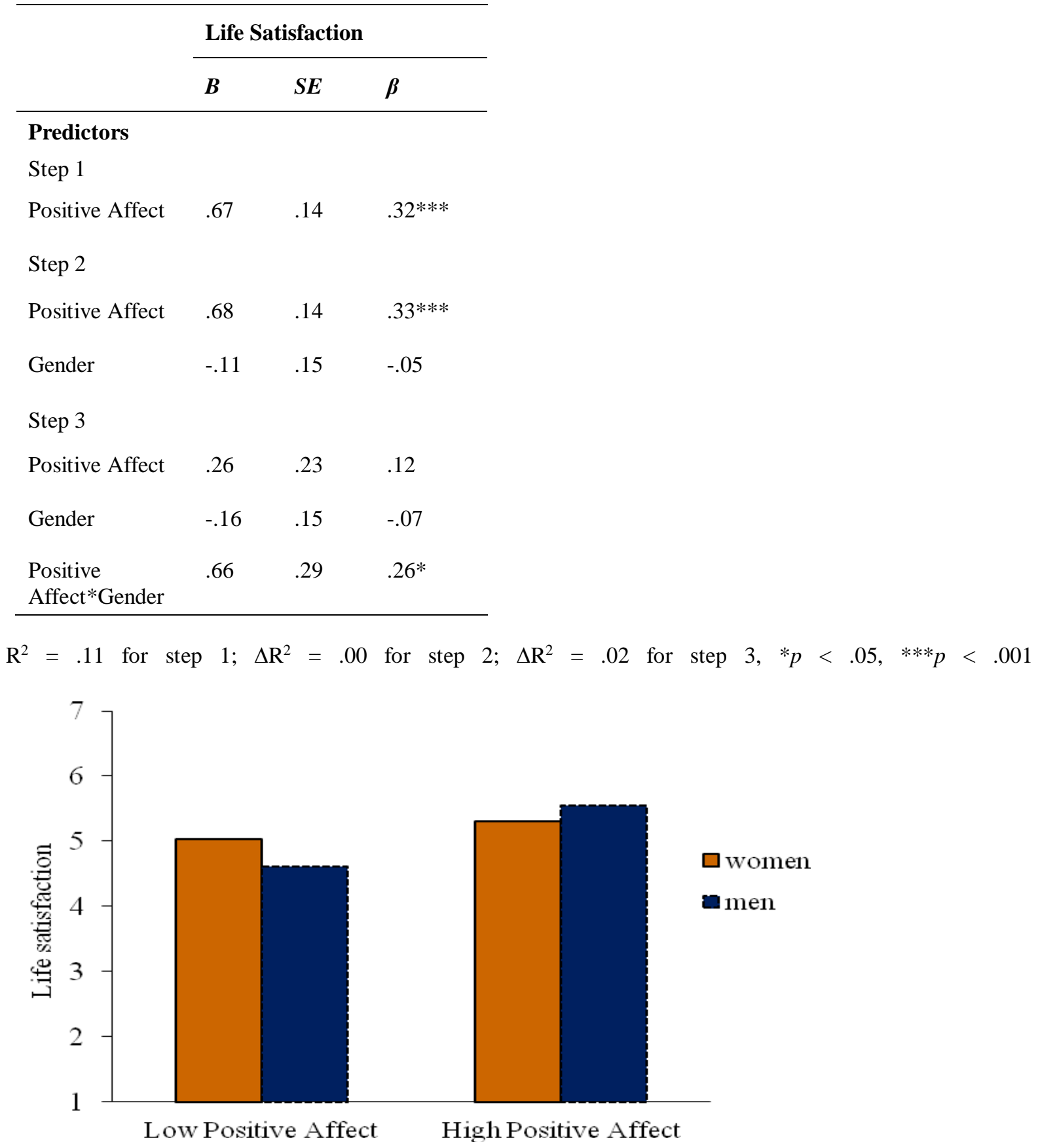

Figure 2. The relationship of high and low positive affect with life satisfaction in men and women. 


\section{Discussion}

The main objective of this study was to determine the relationships among three variables: positive affect, purpose in life and life satisfaction that are important for one's life and well-being. The present study finds a significant relationship between positive affect and purpose in life. People who experience more positive affect seem to have a greater sense of meaning in their lives. Previous studies have demonstrated that experience of positive affect has many desirable outcomes (Fredrickson \& Joiner, 2002; Fredrickson, Tugade, Waugh, \& Larkin, 2003). Particularly, Fredrickson (2001) claims that experiences of positive emotions help individuals broaden their momentary thought-action repertoires as well as develop their physical, intellectual, social and psychological resources. Findings of this study lend support to Fredrickson's view that experience of positive emotions facilitates the building of personal resources such as purpose in life.

The current study also finds a significant relationship between positive affect and life satisfaction. Life satisfaction can be described as one's overall evaluation of various aspects of life (Suh, Diener, \& Oishi, 1998). Positive affect and life satisfaction are two main components of subjective well-being. Affect is considered as the affective element whereas life satisfaction is considered as the cognitive element of subjective well-being (Diener, Suh, Lucas, \& Smith, 1999; Myers \& Diener, 1995). It is believed that an individual with higher level of satisfaction with life and who experiences more positive affect and less negative affect would have a higher level of subjective well-being. A study with three cultural groups: Americans, Indians, and Sri Lankans, showed that Indians were more satisfied with their lives than other groups. In addition, it has indicated that positive affect is positively associated with life satisfaction (Dissanayake, Halberstadt, Kalat, \& Kamble, n.d.). Results of this study support previous findings and strengthen the evidence of a relationship between positive affect and life satisfaction.

Further, correlational analysis revealed a significant relationship between purpose in life and life satisfaction. According to Ryff (1995), purpose in life is one of the key dimensions of psychological well-being. Individuals with a strong feeling of purpose in life tend to believe their lives are meaningful. In addition, they have a strong sense of direction; as a result, they set their life goals and motivate themselves to achieve them. These individuals may experience greater life satisfaction and happiness by accomplishing their goals. A strong sense of meaning in life brings significant benefits for individuals. Having a greater sense of meaning in life is a significant psychosocial predictor of psychological well-being. For example, purpose in life has been significantly related to global happiness (Debats, van deLubbe, \& Wezeman, 1993; Park, Park, \& Peterson, 2010; Ryff \& Keyes, 1995) and life satisfaction (Chamberlain \& Zika, 1988; Ryff, and Keyes, 1995; Scheier et al., 2006; Steger, Kashdan, Sullivan, \& Lorentz, 2008; Steger, Oishi, \& Kashdan, 2009). Results of this study are similar to previous findings and also provide evidence for the link between purpose in life and life satisfaction.

Previous studies have found significant gender differences in purpose in life (Ryff, 1995). Accordingly, young men tend to have a strong feeling of purpose in life when compared to other age groups. The sample of this study also consists of young Indian men and women. In contrast to previous research, present findings indicate that women have a stronger sense of purpose in life than men. This suggests that there may be different factors that contribute to the differences in the perception of life as meaningful in men and women live in different socio-cultural settings. Further, the significant interaction by gender suggests that the effect of positive affect on life satisfaction may be different in men and women. Specifically, the relationship between positive affect and life satisfaction was stronger in men.

In summary, it seems that positive affect clearly plays a significant role in individuals' perceptions of life as meaningful and their life satisfaction. A strong feeling of purpose in life also motivates individuals to achieve goals most meaningful to them and thereby gaining greater satisfaction. Gaining a better understanding of the 
impact of positive affect and other variables on one's life and developing ways to increase positive affect in people, particularly those living with life stressors, will help improve individuals' health and well-being.

\section{References}

Bolte, A., Goschkey, T., \& Kuhl, J. (2003). Emotion and intuition: Effects of positive and negative mood on implicit judgments of semantic coherence. Psychological Science, 14, 416-421.

Cacioppo, J. T., Gardner, W. L., \& Berntson, G. G. (1999). The affect system has parallel and integrative processing components: Form follows function. Journal of Personality and Social Psychology, 76, 839-855.

Carver, C. S., \& Scheier, M. F. (1990). Origins and functions of positive and negative affect: A control-process view. Psychological Review, 97, 19-35.

Chamberlain, K., \& Zika, S. (1988). Religiosity, life meaning, and wellbeing: Some relationships in a sample of women. Journal for the Scientific Study of Religion, 27, 411-420.

Clore, G. L. (1994). Why emotions are felt. In P. Ekman, \& R. Davidson, (Eds.), The nature of emotion: Fundamental questions. (pp. 103-111). New York: Oxford University Press.

Cohn, M., Fredrickson, B., Brown, S., Mikels, J., Conway, A. (2009). Happiness unpacked: Positive emotions increase life satisfaction by building resilience, Emotion, 9, 361-368.

Danner, D. D., Snowdon, D. A., \& Friesen, W. V. (2001). Positive emotions in early life and longevity: Findings from the Nun Study. Journal of Personality and Social Psychology, 80, 804-813.

Davidson, R. J. (1993). The neuropsychology of emotion and affective style. In M. Lewis, J. M. Haviland, (Eds.), Handbook of emotion. (pp.143-154). New York: Guilford Press.

Debats, D. L., Van der Lubbe, P. M., \& Wezeman, F. R. (1993). On the psychometric properties of the Life Regard Index (LRI): A measure of meaningful life. Personality and Individual Differences, 14, 337-345.

Diener, E., \& Suh, E. M. (1999). National differences in subjective well-being. In D. Kahneman, E. Diener, \& N. Schwarz (Eds.). Well-being: The foundations of hedonic psychology. (pp. 434-450) New York: Russell Sage Foundation.

Diener, E., Emmons, R. A., Larsen, R. J., \& Griffin, S. (1985). The satisfaction with life scale. Journal of Personality Assessment, 49(1), 71-75.

Diener, E., Suh, E. M., Lucas, R. E., \& Smith, H. L. (1999). Subjective well-being: Three decades of progress. Psychological Bulletin, 125(2), 276-302.

Dissanayake, M. P., Halberstadt, A. G., Kalat, J. W., \& Kamble, S. V. (2011). The link between emotion differentiation and relationship quality of individuals across cultures. Unpublished manuscript.

Ekman, P. (1994). Moods, emotions, and traits. In P. Ekman \& R. J. Davidson (Eds.), The nature of emotion: Fundamental questions (pp. 56-58). New York: Oxford University Press.

Fredrickson, B. L. (2001). The role of positive emotions in positive psychology: The Broaden-and-Build theory of positive emotions. American Psychologist, 56(3), 218-226.

Fredrickson, B. L. (1998). What good are positive emotions? Review of General Psychology, 2, 300-319.

Fredrickson, B. L., \& Branigan, C. A. (2005). Positive emotions broaden the scope of attention and thoughtaction repertoires. Cognition and Emotion, 19, 313-332.

Fredrickson, B. L., \& Joiner, T. (2002). Positive emotions trigger upward spirals toward emotional well-being. Psychological Science, 13, 172-175.

Fredrickson, B. L., Tugade, M. M., Waugh, C. E., \& Larkin, G. (2003). What good are positive emotions in crises? A prospective study of resilience and emotions following the terrorist attacks on the United States on September 11th, 2001. Journal of Personality and Social Psychology, 84, 365-376.

Isen, A. M., Daubman, K. A., \& Nowicki, G. P. (1987). Positive affect facilitates creative problem solving. Journal of Personality and Social Psychology, 52, 1122-1131.

Kang, S., Shaver, P. R., Sue, S., Min, K., \& Jing, H. (2003). Cultural-specific patterns in the prediction of life satisfaction: Role of emotion, relationship quality, and self esteem. Personality and Social Psychology Bulletin, 29(12), 1596-1608. 
King, L. A., Hicks, J. A., Krull, J. L., \& Del Gaiso, A. K. (2006). Positive affect and the experience of meaning in life. Journal of Personality and Social Psychology, 90, 179-196.

Levy, B. R., Slade, M. D., Kunkel, S. R., \& Kasl, S. V. (2002). Longevity increased by positive self-perceptions of aging. Journal of Personality and Social Psychology, 83, 261-270.

Moskowitz, J. T. (2003). Positive affect predicts lower risk of AIDS mortality. Psychosomatic Medicine, 65, 620-626.

Myers, D. G., \& Diener, E. (1995). Who is happy? Psychological Sciences, 6(1),10-17.

Ostir, G. V., Markides, K. S., Black, S. A., \& Goodwin, J. S. (2000). Emotional well-being predicts subsequent functional independence and survival. Journal of the American Geriatrics Society, 48, 473-478.

Ostir, G. V., Markides, K. S., Peek, K., \& Goodwin, J. S. (2001). The associations between emotional wellbeing and the incidence of stroke in older adults. Psychosomatic Medicine, 63, 210-215.

Ostir, G. V., Smith, P. M., Smith, D., \& Ottenbacher, K. J. (2005). Reliability of the positive and negative affect schedule (PANAS) in medical rehabilitation. Clinical Rehabilitation, 19, 767-769.

Park, N., Park, M., \& Peterson, C. (2010). When is the search for meaning related to life satisfaction? Applied Psychology: Health and Well-Being, 2(1), 1-13.

Rosenberg, E. L. (1998). Levels of analysis and the organization of affect. Review of General Psychology, 2(3), 247-270. doi:10.1037/1089-2680.2.3.247

Rowe, G., Hirsh, J. B., \& Anderson, A. K. (2007). Positive affect increases the breadth of attentional selection. Proceedings of the National Academy of Sciences, USA, 104, 383-388.

Russell, J. A., \& Barrett, L. F. (1999). Core affect, prototypical emotional episodes, and other things called emotion: Dissecting the elephant. Journal of Personality and Social Psychology, 76(5), 805-819. doi:10.1037/0022-3514.76.5.805

Ryff, C. D. (1989). Happiness is everything or is it? Explorations on the meaning of psychological well-being. Journal of Personality and Social Psychology, 57(6), 1069-1081.

Ryff, C. D. (1989a). Beyond de Leon and life satisfaction: New directions in quest of successful aging. International Journal of Behavioral Development, 12, 35-55.

Ryff, C. D. (1995). Psychological well-being in adult life. Current Directions in Psychological Science, 4, $99-$ 104.

Ryff, C. D., \& Keyes, C. L. M. (1995). The structure of psychological well-being revisited. Journal of Personality and Social Psychology, 69(4), 719-727.

Scheier, M. F. et al. (2006). The life engagement test: Assessing purpose in life. Journal Behavioral Medicine, 29(3), 291-298.

Steger, M. F., Kashdan, T. B., Sullivan, B. A., \& Lorentz, D. (2008). Understanding the search for meaning in life: Personality, cognitive style, and the dynamic between seeking and experiencing meaning. Journal of Personality, 76(2), 199-228.

Steger, M. F., Oishi, S., \& Kashdan, T. B. (2009). Meaning in life across the life span: Levels and correlates of meaning in life from emerging adulthood to older adulthood. The Journal of Positive Psychology, 4(1), 43-52.

Steptoe, A., Wardle, J., \& Marmot, M. (2005). Positive affect and health-related neuroendocrine, cardiovascular, and inflammatory responses. Proceedings of the National Academy of Sciences, USA, 102, 6508-6512.

Suh, E., Diener, E., \& Oishi, S. (1998). The shifting basis of life satisfaction judgments across cultures: Emotions versus norms. Journal of Personality and Social Psychology, 74(2), 482-493.

Tellegen, A., Watson, D., \& Clark, L. A. (1999). On the dimensional and hierarchical structure of affect. Psychological Science, 10, 297-303. doi:10.1111/14679280.00157

Trankle, S. A. \& Haw, J. (2009). Predicting Australian health behaviour from health beliefs. Electronic Journal of Applied Psychology, 5, 9-17.

Watson, D., Clark, L. A., \& Tellegen, A. (1988). Development and validation of brief measures of positive and negative affect: The PANAS scales. Journal of Personality and Social Psychology, 54(6), 1063-1070.

Watson, D., Wiese, D., Vaidya, J., \& Tellegen, A. (1999). The two general activation systems of affect: Structural findings, evolutionary considerations, and psychobiological evidence. Journal of Personality and Social Psychology, 76, 820-838. 
Yoo, J., Miyamoto, Y., \& Ryff, C. D. (2016, June 27). Positive Affect, Social Connectedness, and Healthy Biomarkers in Japan and the U.S. Emotion. Advance online publication. http:// dx.doi.org/10.1037/emo0000200

Zika, S., \& Chamberlain, K. (1992). On the relation between meaning in life and psychological well-being. British Journal of Psychology, 83, 133-145. 